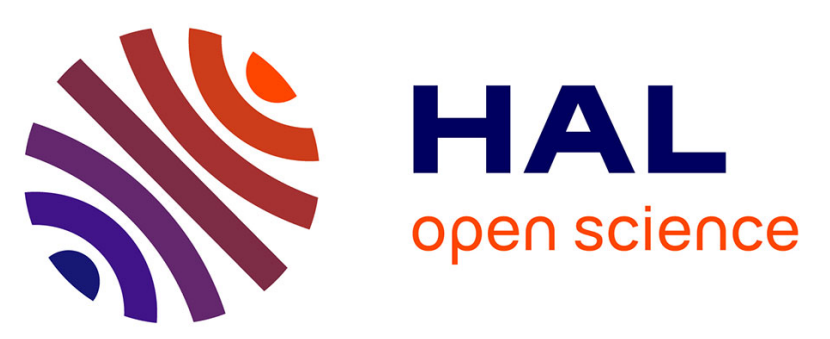

\title{
DUAL-BAND PRINTED DIPOLE ANTENNA ARRAY FOR AN EMERGENCY RESCUE SYSTEM BASED ON CELLULAR-PHONE LOCALIZATION
}

\author{
Guillaume Villemaud, Cyril Decroze, Christophe Dall'Omo, Thierry \\ Monédière, Bernard Jecko
}

\section{To cite this version:}

Guillaume Villemaud, Cyril Decroze, Christophe Dall'Omo, Thierry Monédière, Bernard Jecko. DUAL-BAND PRINTED DIPOLE ANTENNA ARRAY FOR AN EMERGENCY RESCUE SYS-

TEM BASED ON CELLULAR-PHONE LOCALIZATION. Microwave and Optical Technology Letters, 2004, pp. inria-00436616

\section{HAL Id: inria-00436616 \\ https://hal.inria.fr/inria-00436616}

Submitted on 27 Nov 2009

HAL is a multi-disciplinary open access archive for the deposit and dissemination of scientific research documents, whether they are published or not. The documents may come from teaching and research institutions in France or abroad, or from public or private research centers.
L'archive ouverte pluridisciplinaire HAL, est destinée au dépôt et à la diffusion de documents scientifiques de niveau recherche, publiés ou non, émanant des établissements d'enseignement et de recherche français ou étrangers, des laboratoires publics ou privés. 


\title{
DUAL-BAND PRINTED DIPOLE
}

\author{
ANTENNA ARRAY FOR AN
}

EMERGENCY RESCUE SYSTEM BASED

ON CELLULAR-PHONE LOCALIZATION

\author{
G. VILLEMAUD, C. DECROZE, C. DALL'OMO, T. MONEDIERE, B. JECKO \\ IRCOM-CREAPE - 123 avenue Albert Thomas 87060 Limoges Cedex \\ E-mail : guillaume.villemaud@unilim.fr
}

\begin{abstract}
This paper describes our contribution in the RNRT project called LUTECE, dedicated to the emergency localisation of cellular phones. This contribution takes place in the field of antennas, with the development of two biband systems : a directive array for the emission part, and a circular array of five elements with separated outputs for the receiving part. Different evolutions of these antennas are presented starting from the same basic element, finally optimised on a dielectric substrate to offer good mechanical characteristics. All antennas are studied using our FDTD code.
\end{abstract}

Keywords : multiband antenna, direction finding, folded dipole, directive antenna, hybrid array.

\section{INTRODUCTION}

Emergency rescue in case of avalanches statistics reveal for snow-flooded persons that $92 \%$ survive after 15 minutes, but only $30 \%$ survive after 45 minutes. Detection of GSM phones appears to be an easy efficient way to accelerate the localisation of these victims. Numerous examples are well known of people rescued by this way, but only when the phone was in base stations range. For the uncovered areas, no solutions are yet studied.

The project LUTECE, managed by the THALES Communications company, proposes to develop a detection system that can be used on board in an helicopter. This project is labelled by the RNRT (Réseau National de Recherche en Télécommunications) and then funded by the French Ministry of Industry. Such a 
system may allowed fast life saving in desert zones with no need of an important rescue team. Moreover no particular equipment is needed for GSM owners, they only have to put their cellular on wait mode.

To achieve this detection, two different antenna systems are needed, both covering the GSM and DCS bands, while presenting good mechanical characteristics. This paper describes the directive antenna developed for the emission part, and a circular array for the receiving part.

\section{BASIC CONCEPT}

\subsection{System principle}

The LUTECE system mainly consists in a Base Station Simulator connected to a directive antenna, used to awake the cellular phone, and a circular array of five antennas, receiving the uplink signal and allowing a DOA (Direction of Arrival) determination (figure 1). Then the helicopter's pilot can be constantly informed of the target's direction.

\subsection{Antenna needs for the emission part}

To achieve a good compromise between a large enough footprint and a sufficient level of gain, an emitting antenna with a halfpower beamwidth of about $45^{\circ}$ is required (horizontally polarised).

This antenna also needs to present good matching characteristics (VSWR<2) for all GSM and DCS bands.

Furthermore, a mechanical beamsteering will be provided by a tilted platform, in order to cover an area forward the helicopter.

\subsection{Receiving antennas}

Five antennas are needed to operate a good goniometry of the uplink signal. Moreover, these antennas has to form a circular array with separated outputs. Phase and magnitude of the received signal on each antenna are then analysed with a MUSIC-type algorithm to calculate the DOA. 
These elements only have to cover the uplink bands for GSM and DCS standards. Large enough apertures are required for each antenna (about $80^{\circ}$ ), with an horizontal polarisation. Coupling coefficients between those elements also have to be studied and minimised.

\section{BASIC ANTENNA ELEMENT}

\subsection{Working principle}

The basic element consists in a folded dipole associated to a limited groundplane [1]. This limitation of the ground allows to obtain large bandwidths, acting as a load when the last part of the dipole is widened [2]. Then to achieve a directive radiation pattern, this structure is placed above a larger ground plane used as a reflector [3]. Afterwards the whole structure is modelled and simulated using a FDTD code, including the rigid coaxial cable jointing the upper and the lower groundplane. The height between the two grounds is then adjusted to optimise the bandwidths while conserving a relatively low profile.

\subsection{Experimental results}

The first topology developed and fabricated is presented on figure 2 . The lower ground plane used is a 35 by $35 \mathrm{~cm}$ one, and the overall height represents $48 \mathrm{~mm}$. Foam pieces are added to strengthened the structure.

Measurements results show a very good agreement between predicted and effective performances of this element. Large bandwidths are obtained (figure 3) together with good radiated characteristics. A maximum gain of $10 \mathrm{dBi}$ is achieved in the GSM band with halfpower beamwidths of about $70^{\circ}$ and a maximum gain of $7 \mathrm{dBi}$ for the DCS band with $100^{\circ}$ apertures.

\section{EMITTING ANTENNA RESULTS}

\subsection{On air substrate}

Considering the good performances of this basic element, a four elements array based on this topology has been developed to achieve the desired aperture. Due to the biband working of this array, an optimal distance 
between the elements has to be found to offer the best compromise relatively to the different wavelengths. The proposed structure after FDTD study is shown on figure 4.

As previously, the measurements are in very good agreement with the calculations. The GSM and DCS bandwidths are then largely covered (figure 5).

The obtained radiation patterns are also similar to the predicted ones. Figure 6 presents the normalised radiation patterns at GSM and DCS frequencies for the vertical plane corresponding to the larger dimensions of the array.

The measured maximum gain is $13.5 \mathrm{dBi}$ for the GSM band, for an average halfpower beamwidth of $54^{\circ}$, and $13.7 \mathrm{dBi}$ for the DCS band, with an average aperture of $43^{\circ}$.

By the way, this array offers good matching and radiating characteristics, unfortunately along with relatively poor mechanical characteristics, even if foam reinforcements are used.

\subsection{On dielectric substrate}

To prevent mechanical problems, a new solution using a dielectric substrate was explored. The idea is then to print directly the dipoles and the upper grounds on each faces of a $3.175 \mathrm{~mm}$ height substrate (permittivity 2.33).

By the way, a new design of the basic element is performed, offering smaller dimensions of only $80 x 64$ $\mathrm{mm}$. This new structure presents narrower bandwidths, but still large enough to cover the desired frequencies.

A four elements array based on this new element was modelled and optimised, finally much more compact than the previous one $(194 \times 170 \mathrm{~mm})$. This array has good matching characteristics, but presents an inappropriate halfpower beamwidth of $62^{\circ}$ for the GSM frequencies and also some important sidelobes.

Therefore, in order to obtain better performances, an innovative structure was developed, composed of a four biband elements array with a DCS-only element inserted at the center (figure 7). We have then achieved a four elements array for GSM frequencies associated to a five elements array for the DCS band. The spacing between elements can now be more easily adjusted, allowing narrower apertures and lower sidelobes (figure 8).

Regarding these encouraging results, a specific feeding circuit has been studied. This circuit will be placed under the lower ground plane and will provide a feeding of each element with the same phase.

\section{RECEIVING ANTENNAS RESULTS}


Nearly the same basic element on dielectric substrate is also intended to be used to receive the uplink signal.

Five separated antennas are needed, with a circular disposition (figure 9). Numerical studies have shown that to consider the coupling coefficients between elements negligible (minor than $-30 \mathrm{~dB}$ ), a very large diameter of the circle is required. Considering the limited space allowed under an helicopter, a close disposition of the elements has been chosen, along with coupling matrix implementation in the DOA algorithm.

Even with such close spacing (approximately $140 \mathrm{~mm}$ between two antennas), good matching characteristics are kept, with predicted maximum gains of about $6 \mathrm{dBi}$

\section{CONCLUSION}

Different kinds of antenna systems have been presented in this paper, all based on the same basic element : a folded dipole presenting large bandwidths.

In the field of the LUTECE RNRT project, a directive hybrid five elements array on dielectric substrate allows an efficient emission for cellular phones awaking.

Moreover, five identical antennas disposed in circle can offer good performances to determine the direction of the uplink signal.

\section{ACKNOWLEDGEMENT}

We wish like to thanks all partners of the LUTECE project, particularly to the RNRT.

\section{REFERENCES}

1. G. Villemaud, C. Decroze, F. Torres, T. Mone'die`re, B. Jecko, Multiband antenna for mobile communication standards, Int Conf Antenna

Technol Appl Electromagn, Montre'al, 2002, pp. 533-536.

2. S.S. Sandler and R.W.P. King, Compact conical antennas for wideband coverage, IEEE Trans Antennas Propagat 42 (1994), 436-439.

3. H.C. Tung, S.T. Fang, and K.L. Wong, Printed dual-band monopole 
antenna for 2.4/5.2-GHz WLAN access point, Microwave Opt Techonol Lett 35 (2002), 286-288.

4. T.Y. Wu, S.T. Fang, and K.L. Wong, Printed monopole array antenna for WLAN operation in the 2.4/5.8-GHz band, Microwave Opt Techonol Lett 37 (2003), 370-372.

5. J.D. Kraus, Antennas, 2nd ed., McGraw-Hill, New York, 1988, pp. $462-464$.

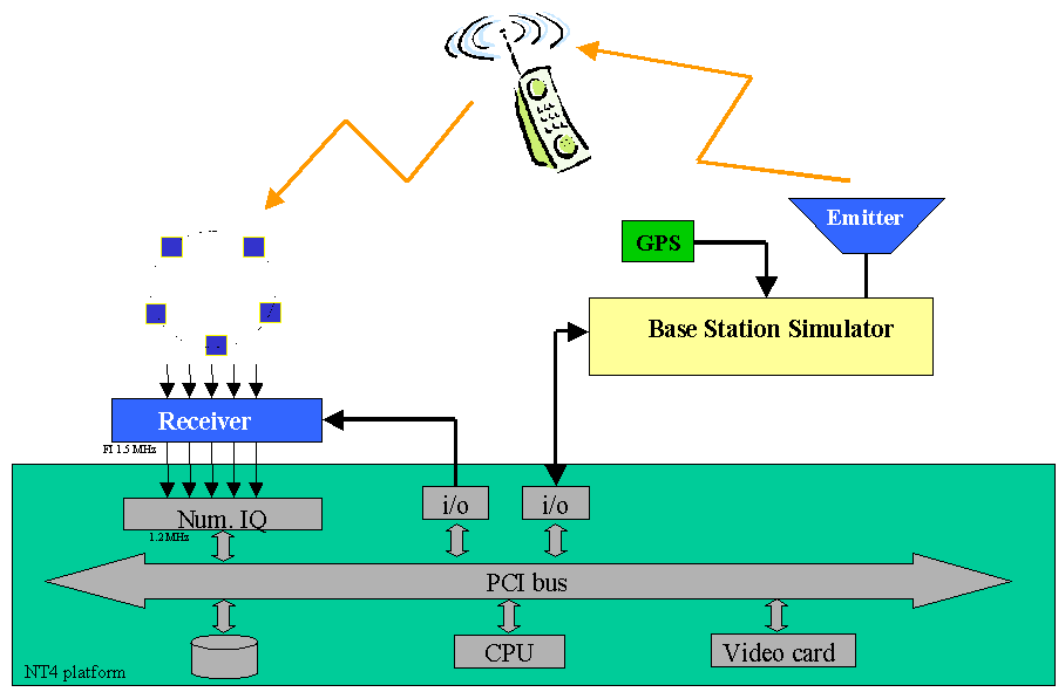

Fig. 1 : LUTECE system structure

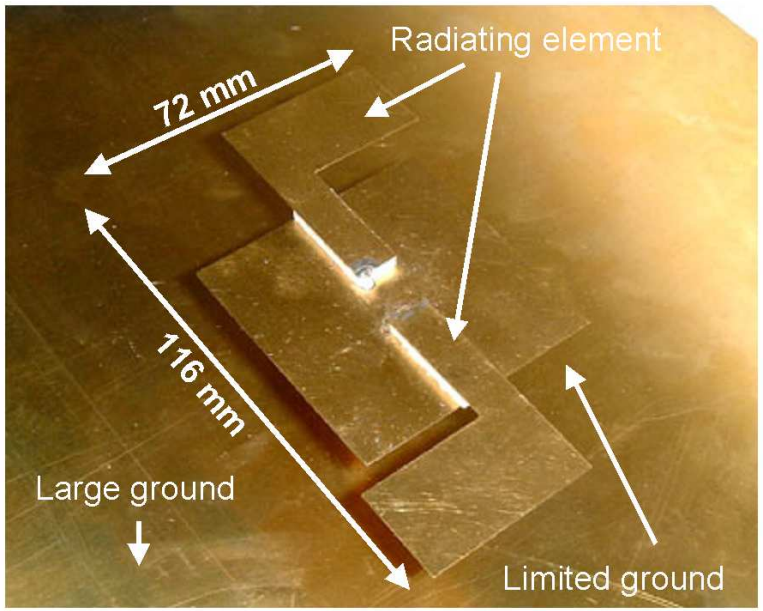

Fig. 2 : Prototype of the basic element 


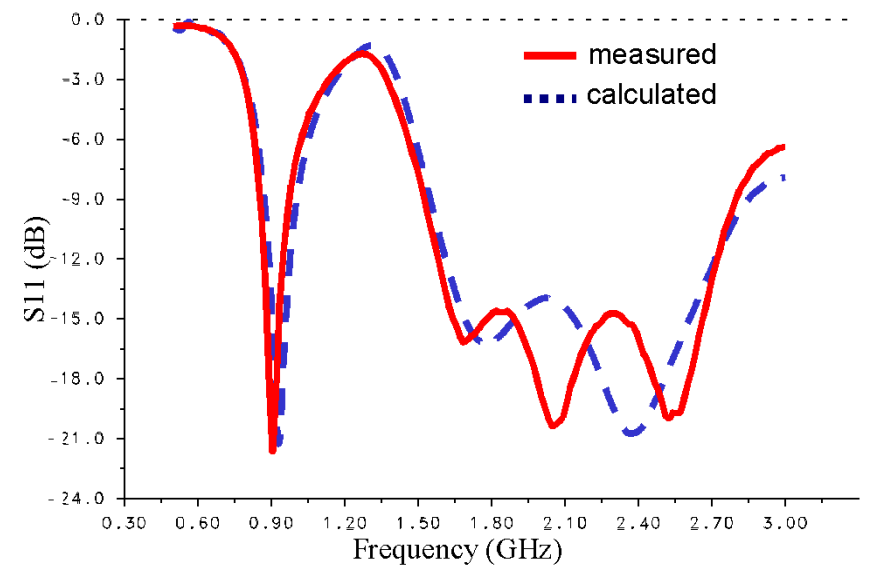

Fig. 3 : Comparative return losses

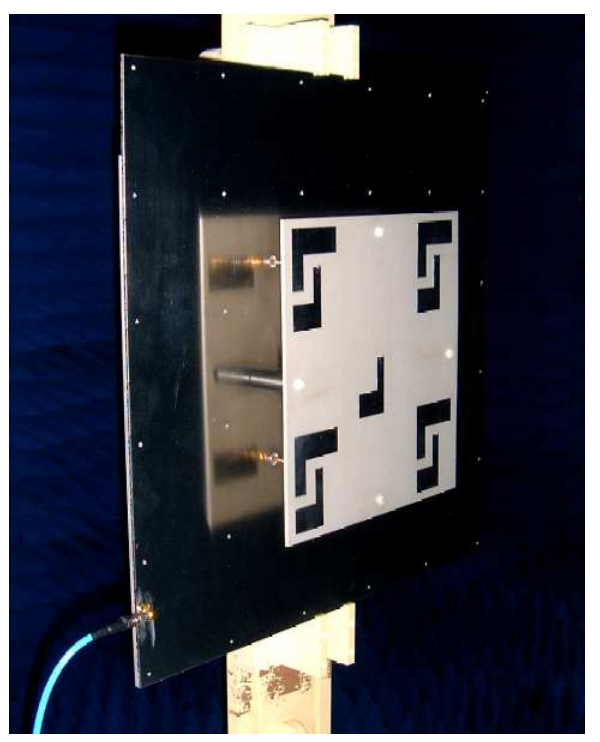

Fig. 4 : Prototype of the four elements array

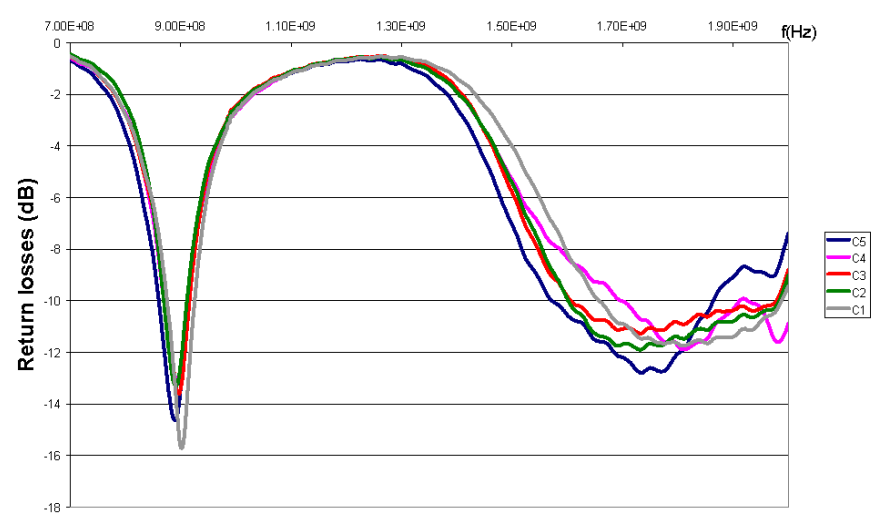

Fig. 5 : Return loss of each element 

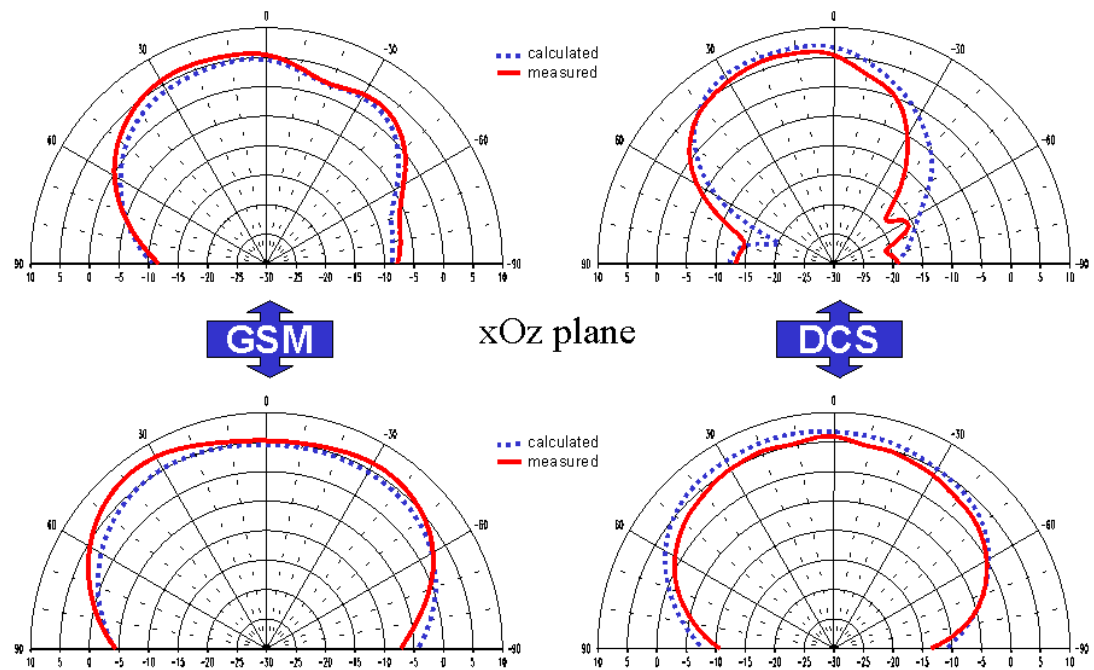

yOz plane

Fig. 6 : Comparative radiation patterns

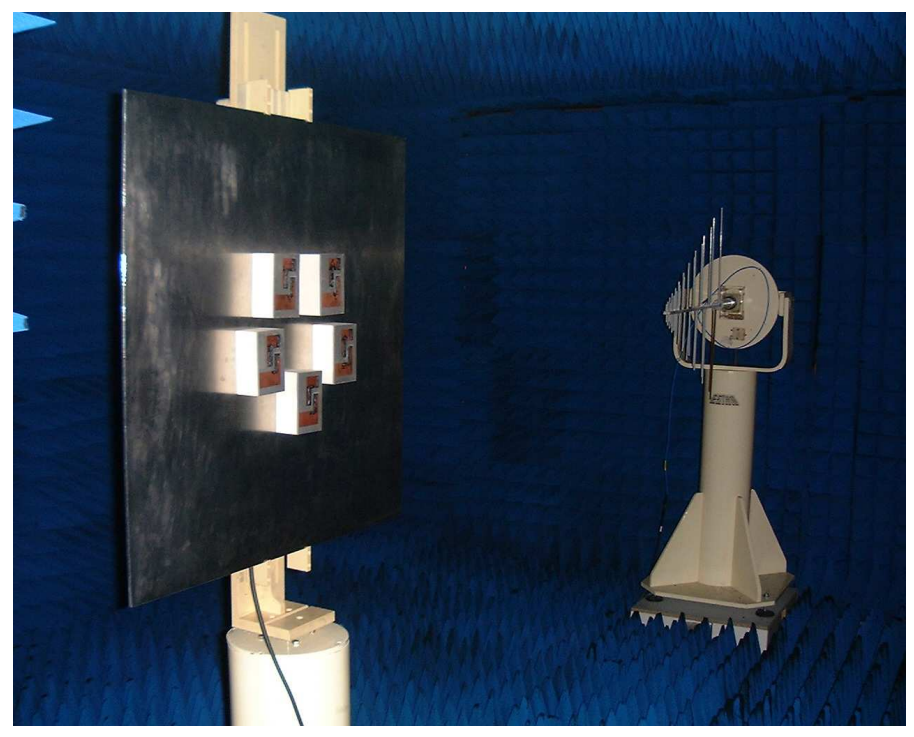

Fig. 7 : Structure of the five elements array 